\title{
VESICOURETHRAL ANASTOMOSIS FACILITATED BY A NEW DISPOSABLE INSTRUMENT
}

\author{
ANTONIO C. DI PIERO \\ Section of Urology, Municipal Hospital Dr Mário Gatti, Campinas, São Paulo, Brazil
}

\begin{abstract}
The author presents a prototype of a disposable device that enables, in one single movement, the passing of all suture stitches in the urethral stump that will be anastomosed to the bladder or to a neobladder, with the advantage of a regular distribution of these stitches around the urethral circumference. In tests with animals, the device showed to be easily applicable, effective and safe.
\end{abstract}

Key words: prostatectomy; cystectomy; vesicourethral anastomosis; device; pigs

Int Braz J Urol. 2004; 30: 323-6

\section{INTRODUCTION}

Since the pioneer studies by Walsh et al. (1), radical prostatectomy has become popular throughout the world. However, the vesicourethral anastomosis is still regarded as the critical part in this surgery. The difficulty is due to the retraction and collapse of the urethral stump, to the restricted access, and restricted space at this pelvic site (2). Overcoming such obstacles would make the procedure less extensive, with a more adequate anastomosis, reducing the index of complications such as urine extravasation, prolonged catheterization, stenosis of the anastomosis and urinary incontinence (3).

Some techniques have been reported aiming to aid in the reconstruction of the urinary tract, including simultaneous urethroscopy, maneuvers that push or pull the urogenital diaphragm towards the bladder neck, special catheters that reveal the urethral lumen and guide suture needles, specific intrapelvic retractors, modified suture techniques, special forceps and even organic adhesives (4).

None of these alternative techniques has been universally established and direct vesicourethral anas- tomosis is still the standard method for reconstruction following radical prostatectomy $(3,5)$.

\section{SURGICAL TECHNIQUE}

The new instrument for passing the stitches on the urethral stump is composed by a silicone piston with one of the extremities tapered. This piston has 6 almost straight surgical needles inserted by the extremity that is connected to the suture around its circumference, in a 45-degree angle. This silicone is tightly inserted into a cylinder (Figure-1) so that the 6 needles close next to the silicone and inside the cylinder (Figure-2). The device is ready to be inserted in the urethral stump (Figure-3) until the cylinder's margin (Figure-4). At this moment the lock (pin) is removed, keeping the cylinder fixed and pushing the silicone piston until the surgeon can feel the needles opening in the urethral lumen. The cylinder is completely removed (Figure-5) and the piston is pulled until the 6 needles are exteriorized through the urethral wall (Figure-6). Each needle is pulled (Figure-7), trespassing the corresponding suture through the urethra (Figure-8). The procedure 


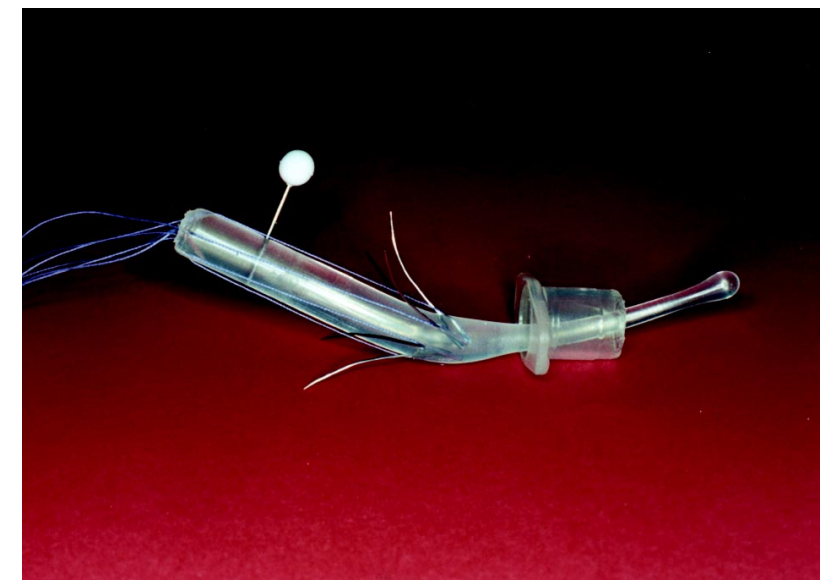

Figure 1 - Device showing the needle-piston as it is inserted in the cylinder.

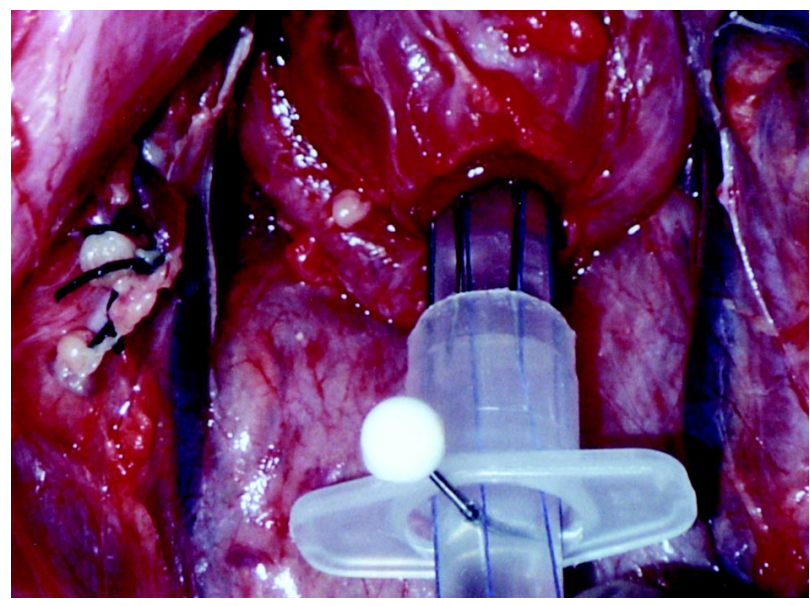

Figure 3 - Device being introduced into the animal's urethral stump.

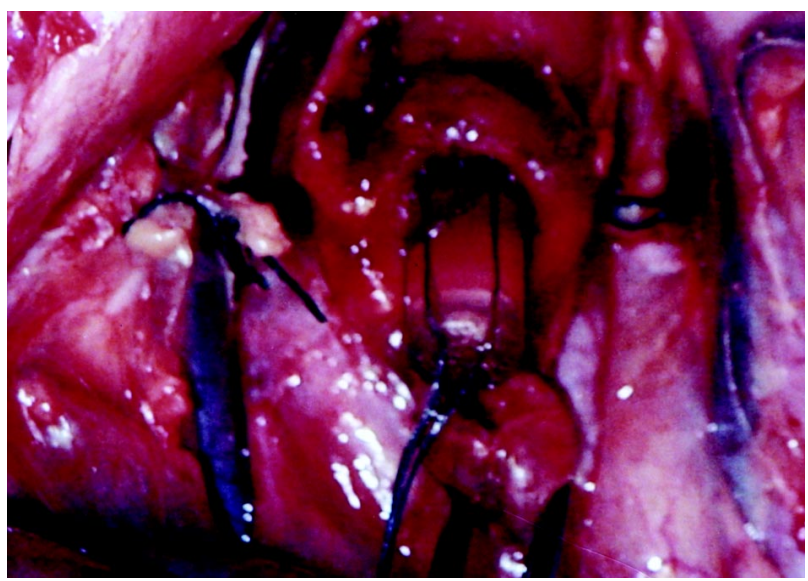

Figure 5 - Piston with open needles inside the urethral lumen.

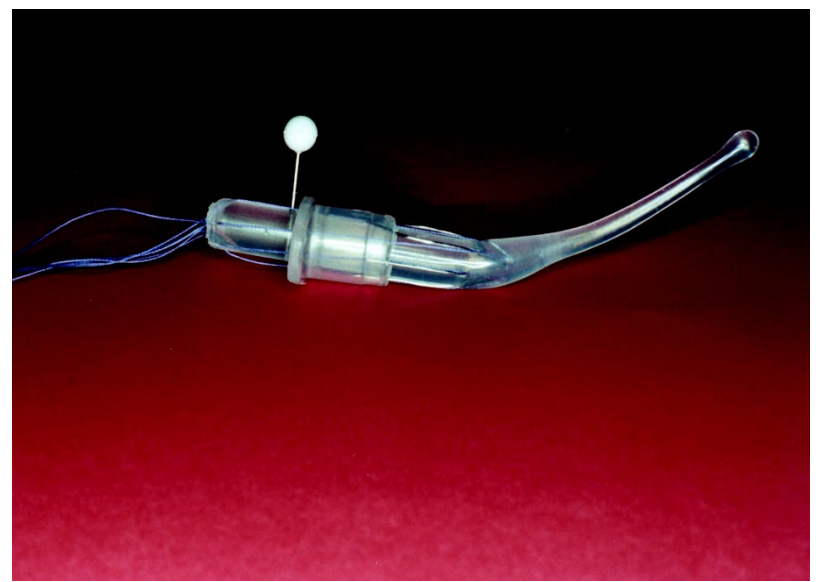

Figure 2-Device showing the needles closed inside the cylinder.

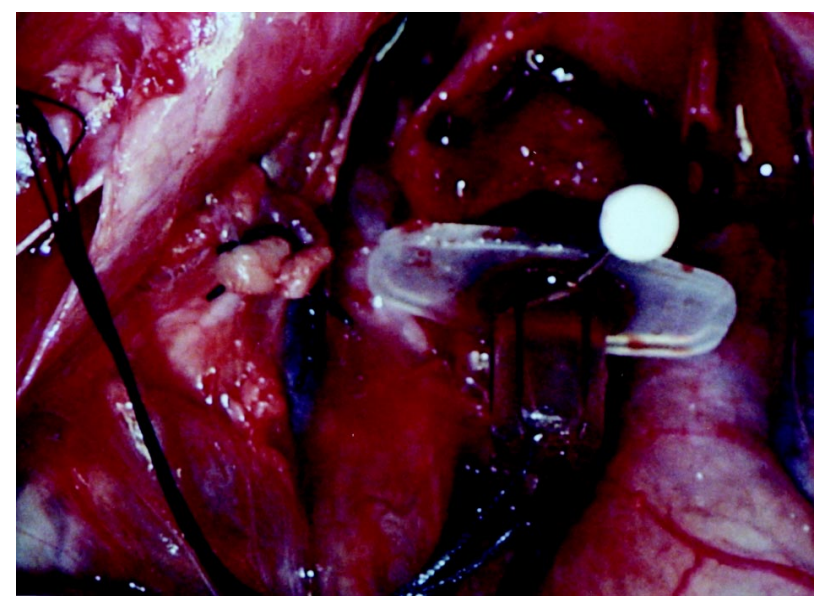

Figure 4-Device correctly inserted.

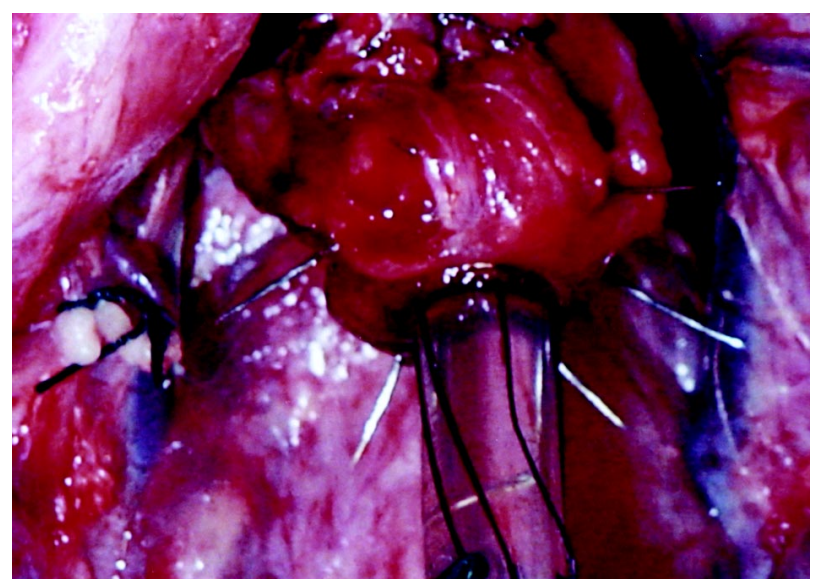

Figure 6-Exteriorization of all needles after piston traction. 


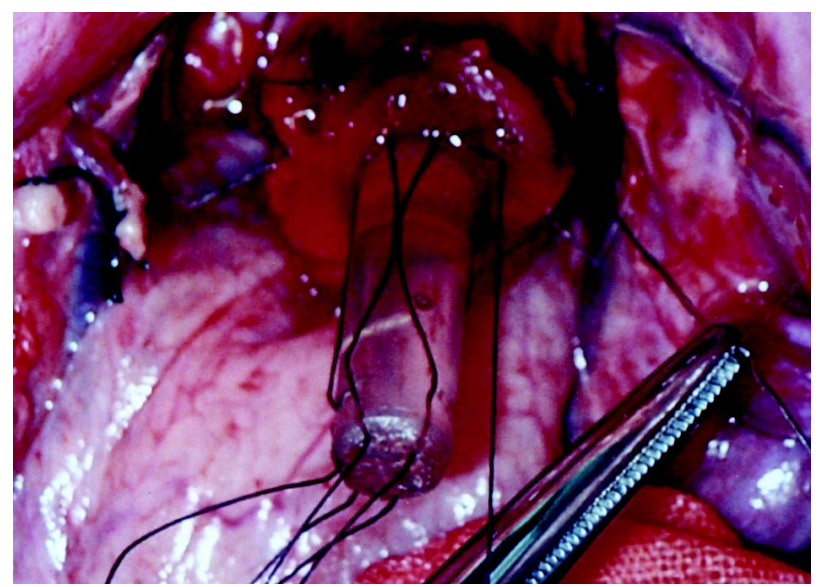

Figure 7 - Needle traction for passing the stitch.

is repeated with the other needles until the 6 stitches are completed (Figure-9), when the urethral stump is then ready to be anastomosed to the bladder or to a neobladder.

This instrument can be useful in laparoscopic radical prostatectomy as well, since the vesicourethral anastomosis is performed with great difficulty during this surgery.

In our experiment, the device location in the urethral stump was easily performed in 10 procedures in pigs, and in all of them, the mechanism of opening and passing of needles through the urethra worked as devised by the author.

The prototype used in the animals was manufactured in a quite simple way. A 4-0 polyglactin needle-suture was used with a $2-\mathrm{cm}$ curve needle, which was manually rectified and inserted in the piston. In the other extremity of the suture, the use of a separate curve needle was required for passing the stitch on the bladder neck.

\section{COMMENTS}

This device serves only as a vehicle for the 6 surgical needles, using the urethral lumen as access route and enabling the simultaneous passing of all stitches with a regular distribution around the urethral circumference. In animal experiments, this new disposable instrument showed to be easily handled,

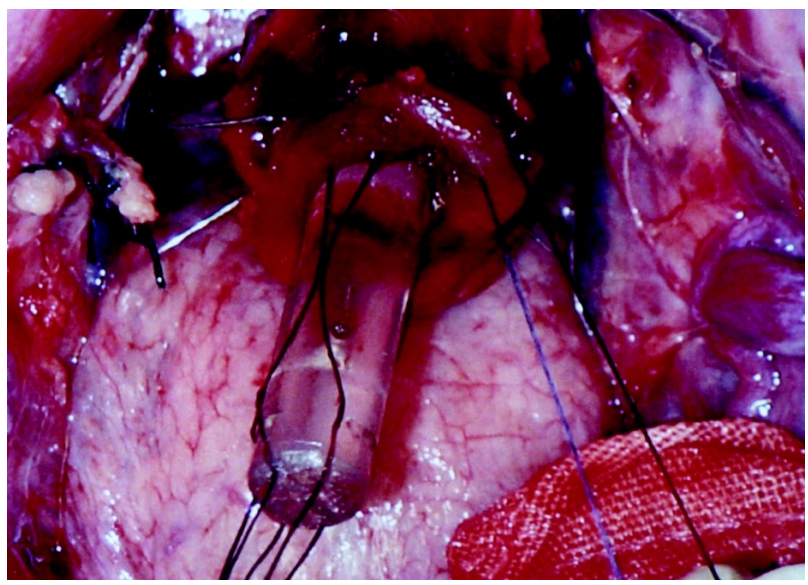

Figure 8 - First stitch passed.

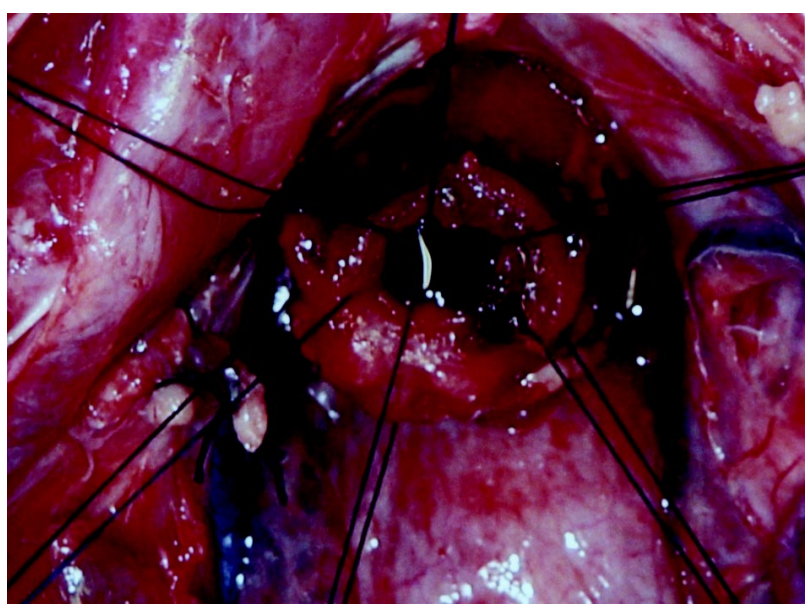

Figure 9-All stitches passed in the urethral stump.

efficient and safe. With the prototype's technological improvement, it is expected that those results can be reproduced in humans.

\section{REFERENCES}

1. Walsh PC, Lepor H, Eggleston JC: Radical prostatectomy with preservation of sexual function: anatomical and pathological considerations. Prostate. 1983; 4: 473-85.

2. Selikowitz SM, Albala DM: A method of exposing the vesicourethral anastomotic site during radical retropubic prostatectomy. J Urol. 1995; 154: 1461-2.

3. Novicki DE, Larson TR, Andrews PE, Swanson SK, Ferrigni RG: Comparison of the modified vest and the 
direct anastomosis for radical retropubic prostatectomy. Urology. 1997; 49: 732-6.

4. See WA: Council-tip catheter facilitates vesicourethral anastomotic suture placement. Urology. 1995; 46: 4012 .

\section{Correspondence address:}

Dr. Antonio Celso Di Piero

Rua Francisco Bueno de Lacerda, 220 / 74

Campinas, SP, 13030-210, Brazil

Fax: + 55 19 3231-8992

E-mail:dipiero@ligbr.com.br
5. Yamada Y, Honda N, Nakamura K, Mitsui K, Hibi H, Taki T, et al.: Vesicourethral anastomotic suture placement during radical prostatectomy using Maniceps. Urol Int. 2003; 70: 181-5.

Received: April 12, 2004 Accepted after revision: August 12, 2004

\section{EDITORIAL COMMENT}

The author presents an ingenious alternative, which at first site seems useful and feasible. However, it is important to point that in more delicate and retracted urethras, the needles could transfix improper sites, and may include little urethral tissue, eventually even rupturing it, without an adequate coapta- tion with the bladder. On the other hand, it may include excessive urethral tissue, which could involve the sphincteric complex.

The author must be commended and the urologic community anxiously waits for clinical results.
Dr. Marcos F. Dall'Oglio

Section of Urology Federal University of São Paulo, UNIFESP São Paulo, SP, Brazil 